\title{
Intra-aortic balloon pumps and continuous flow left ventricular assist devices: Don't let balloon pumps overstay their welcome
}

\author{
Kevin G. Soucy, PhD, Steven C. Koenig, PhD, and Mark S. Slaughter, MD
}

\footnotetext{
From the Departments of Cardiovascular and Thoracic Surgery and Bioengineering, University of Louisville, Louisville, Ky.

Disclosures: Authors have nothing to disclose with regard to commercial support.

Received for publication Sept 19, 2016; accepted for publication Sept 19, 2016; available ahead of print Oct 22, 2016.

Address for reprints: Mark S. Slaughter, MD, Department of Cardiothoracic Surgery, University of Louisville, 201 Abraham Flexner Way, Suite 1200, Louisville, KY 40202 (E-mail: mark.slaughter@louisville.edu).

J Thorac Cardiovasc Surg 2017;153:e9-10 $0022-5223 / \$ 36.00$

Copyright (c) 2016 by The American Association for Thoracic Surgery http://dx.doi.org/10.1016/j.jtcvs.2016.09.046
}

In this issue of the Journal, Banerjee and colleagues ${ }^{1}$ present a case report of a patient with heart failure who was simultaneously supported by an intra-aortic balloon pump (IABP) and a continuous-flow left ventricular assist device (CF-LVAD; HeartAssist5; ReliantHeart Inc, Houston, Tex). In this case, they observed a reduction in the left ventricular assist device outflow in the immediate postoperative period after CF-LVAD support was initiated. Historically, elective, preoperative IABP support has been successfully used for heart transplant and CF-LVAD placement. $^{2,3}$ Banerjee and colleagues ${ }^{1}$ speculate that postoperative continuation of IABP support may be detrimental to clinical outcomes once patients are supported with a CF-LVAD. The case report of Banerjee and colleagues ${ }^{1}$ is missing some essential data, however, which limits the ability to assess their postulation critically. Specifically, mean arterial pressure, device flow and pump speed, degree of mitral insufficiency, position of the ventricular septum, and any aortic valve opening were not reported. It therefore is difficult to determine whether any decrease in the CF-LVAD flow was from the IABP, the CF-LVAD pump management, other aspects of patient management, or some combination.

Simultaneous IABP and CF-LVAD support raises several questions. First, what is the rationale for continuing IABP support postoperatively after CF-LVAD implantation? Banerjee and colleagues ${ }^{1}$ do not provide a justification warranting continued IABP support in the postoperative period in the first place. CF-LVADs are more effective in restoring flow in patients with end-stage heart failure than are IABPs. Further, any improvement in coronary perfusion provided by an IABP is likely to be negated by the CF-LVAD, and afterload reduction is easily achieved medically and directed toward optimizing pump performance rather than that of the native left ventricle. What improvements might be achieved by continuing IABP support in the postoperative period and whether these improvements are clinically beneficial therefore need to be clarified.

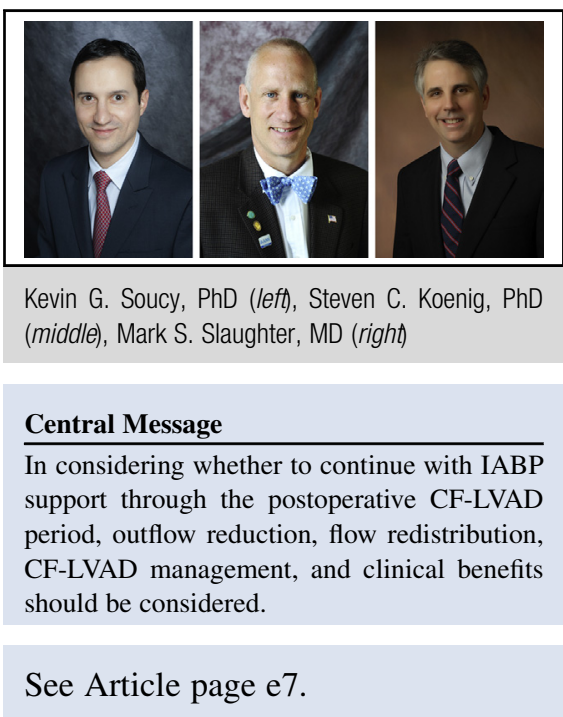

Banerjee and colleagues ${ }^{1}$ also suggest that the preoperative benefits of an IABP might be outweighed by the theoretic risks associated with continuing its use in the postoperative period. The most persuasive rationale for instituting IABP support preoperatively would be the association of such support with improvement of preoperative right ventricular function, with an associated decrease in right heart failure after CF-LVAD implantation. ${ }^{4,5}$ This improvement generally occurs over the course of several days of preoperative IABP support intended to help stabilize the patient and reduce the risk of perioperative right heart failure. After successful CF-LVAD implantation, however, the preoperative benefits of IABP support are markedly diminished if not absent. Finally, it has been shown that counterpulsation with an IABP produces retrograde flow. ${ }^{6}$ Similarly, CF-LVADs operating in less than ideal hemodynamic situations can also generate retrograde flow. ${ }^{7}$ These adverse conditions include (1) pump stoppage, (2) high mean arterial pressure while running at low pump speeds, and (3) intermittent aortic occlusion. Retrograde flow in the CF-LVAD outflow graft is clearly detrimental, but it almost always can be prevented by optimizing pump and patient hemodynamic interaction.

Overall, there is ample evidence that the preoperative use of an IABP to support appropriately selected patients who will be receiving a CF-LVAD can improve outcomes. Continued IABP use in the postoperative period, however, 
would have limited if any added benefit relative to the support already provided by the CF-LVAD. Unless there is a clear purpose for continuing its use in the perioperative period, the IABP should therefore be operated in the flutter mode or with minimal balloon inflation until it can be safely removed. Continued counterpulsation with intermittent aortic occlusion will only reduce the effects of the CF-LVAD and potentially result in retrograde flow.

\section{References}

1. Banerjee D, Choi C, Ha R. Intra-aortic balloon pump therapy negatively affects flow through a continuous-flow left ventricular assist device. J Thorac Cardiovasc Surg. 2017;153:e7-8.

2. Imamura T, Kinugawa K, Nitta D, Hatano M, Kinoshita O, Nawata K, et al Prophylactic intra-aortic balloon pump before ventricular assist device implantation reduces perioperative medical expenses and improves postoperative clinical course in INTERMACS profile 2 patients. Circ J. 2015;79:1963-9.

3. Norkiene I, Ringaitiene D, Rucinskas K, Samalavicius R, Baublys A, Miniauskas S, et al. Intra-aortic balloon counterpulsation in decompensated cardiomyopathy patients: bridge to transplantation or assist device. Interact Cardiovasc Thorac Surg. 2007;6:66-70.

4. Patil NP, Mohite PN, Sabashnikov A, Dhar D, Weymann A, Zeriouh M, et al. Preoperative predictors and outcomes of right ventricular assist device implantation after continuous-flow left ventricular assist device implantation. J Thorac Cardiovasc Surg. 2015;150:1651-8.

5. Drakos SG, Janicki L, Horne BD, Kfoury AG, Reid BB, Clayson S, et al. Risk factors predictive of right ventricular failure after left ventricular assist device implantation. Am J Cardiol. 2010;105:1030-5.

6. Giridharan GA, Bartoli CB, Spence PA, Dowling RD, Koenig SC. Counterpulsation with Symphony prevents retrograde carotid, aortic, and coronary flows observed with intra-aortic balloon pump support. Artif Organs. 2012;36:600-6.

7. Giridharan GA, Koenig SC, Soucy KG, Choi Y, Pirbodaghi T, Bartoli CR, et al. Hemodynamic changes and retrograde flow in LVAD failure. ASAIO J. 2015;61: 282-91. 